\title{
Prevalence of Transfusion Transmitted Infection in Healthy Blood Donors in Sir Salimullah Medical College Dhaka, Bangladesh
}

\author{
${ }^{1}$ Shasanka Kumar Saha, ${ }^{1}$ Ranjit Kumar Banik, ${ }^{2}$ Mili Rani Saha, ${ }^{3}$ Munshi M Habibullah, ${ }^{4}$ Mamun-Al-Mahtab \\ ${ }^{1}$ Department of Gastroenterology, Sir Salimullah Medical College, Mitford Hospital, Dhaka, Bangladesh \\ ${ }^{2}$ Department of Microbiology, Sir Salimullah Medical College, Dhaka, Bangladesh \\ ${ }^{3}$ Department of Blood Transfusion, Sir Salimullah Medical College, Mitford Hospital, Dhaka, Bangladesh \\ ${ }^{4}$ Department of Hepatology, Bangabandhu Sheikh Mujib Medical University, Dhaka, Bangladesh
}

Correspondence: Mamun-Al-Mahtab, Assistant Professor, Department of Hepatology, Bangabandhu Sheikh Mujib Medical University, Shahbagh, Dhaka-1000, Bangladesh, e-mail: shwapnil@agni.com

\section{ABSTRACT}

Background: Transfusion of blood and blood components, as a specialized modality of patient management, saves millions of lives worldwide each year and reduce morbidity. It is well-known that blood transfusion is associated with a large number of complications.

Objective: The objective of the present study was to assess the status of transfusion transmitted infections (TTI) among the apparently healthy donors so as to increase the awareness of complications of blood transfusion and make the clinicians more vigilant with regard to judicious use of blood.

Methods: A total of 21,966 units of donor's blood were screened from January 2007 to December 2010 at blood bank of Sir Salimullah Medical College, Mitford Hospital, Dhaka. All the samples were screened for hepatitis B surface antigen (HBsAg), hepatitis C virus (HCV), human immunodeficiency virus (HIV) 1 and 2, venereal disease research laboratory test (VDRL) and malaria. All healthy blood donors were 18 to 60 years old.

Result: Prevalence of hepatitis B virus (HBV), HCV, HIV and syphilis were 2.19, $0.25,0.06$ and $0.15 \%$ respectively. No blood donor tested showed positivity for malarial parasite. With the implementation of strict donor selection criteria and use of sensitive screening test, it may be possible to reduce the incidence of TTI in the Bangladeshi population.

Abbreviations: HBsAg: Hepatitis B surface antigen; HCV: Hepatitis C virus; HIV 1 and 2: Human immunodeficiency virus 1 and 2; VDRL: Venereal disease research laboratory test; HBV: Hepatitis B virus; NAT: Nucleic acid amplification testing; TTI: Transfusion transmitted infection.

Keywords: Transfusion transmitted infection (TTI), Seroprevalence, Human immunodeficiency virus (HIV), Hepatitis C virus.

\section{INTRODUCTION}

Preventing the transmission of infectious diseases through blood transfusion in developing countries like Bangladesh is difficult. In developing countries like Bangladesh blood safety remains an issue of major concern. Nowadays in Bangladesh routine screening of healthy blood donors is done for hepatitis B virus (HBV), hepatitis C virus (HCV), human immunodeficiency virus (HIV), syphilis and malaria. The priority objective of blood transfusion service is to ensure safety, adequacy, accessibility and efficiency of blood supply at all levels. These strategies have been extremely effective, ${ }^{1,2}$ but transmission of diseases still occurs, ${ }^{3}$ because of the inability of the test to detect the disease in the preseroconversion or window phase of their infection, immunologically variant viruses, nonseroconverting chronic or immunosilent carriers and laboratory testing errors. ${ }^{4}$ This study was undertaken to know the prevalence rate of infectious markers among blood donors.

\section{MATERIALS AND METHODS}

A total of 21,966 units of blood were collected from donors (voluntary and replacement) from January 2007 to December 2010 at blood bank of Sir Salimullah Medical College, Mitford Hospital, Dhaka, Bangladesh. Donors were selected by taking history, clinical examination and following strict donors selection criteria to eliminate professional donors. All the samples were screened for hepatitis B surface antigen (HBsAg), HCV, HIV 1 and 2, VDRL and malaria. All the reactive samples were repeat tested before labeling them seropositive and respective blood units were discarded. 


\section{RESULTS}

A total of 21,966 blood donors were screened in last 4 years. The numbers of donations have gradually increased during the last 4 years from 3400 in 2007 to 7561 donations in 2010. The results of seropositive samples for HBsAg, HCV, HIV and VDRL are shown in Table 1. A gradual increase in seropositive samples of HBsAg, HCV and VDRL was observed in last 3 years, whereas gradual increase rate for HIV was observed for 4 years. No blood donors were tested positive for malaria parasite.

\section{DISCUSSION}

In developed countries the risk of transfusion-transmitted infection is very low, primarily because of success in preventing HIV and other established transfusiontransmitted viruses from entering the blood supply. ${ }^{5}$ This is not same in developing countries, like Bangladesh. Studies in the West have shown that the estimated risk of transfusion-transmitted HIV, HCV and to a lesser extend HBV infection via blood products is very low. ${ }^{6-8}$ Glynn et al ${ }^{9}$ reported that since the introduction of nucleic acid amplification testing (NAT) in the screening procedure of blood donations, the estimated risk of HCV and HIV infections has decreased significantly.

HBV is a major source of transfusion-transmitted hepatitis and is associated with a carrier state, acute hepatitis, chronic liver disease, liver cirrhosis and hepatocellular carcinoma. In the present study, the incidence of HBsAg was $1.5 \%$ in 2007, 1.37\% in 2008, 2.43\% in 2009 and 2.96\% in 2010 and overall incidence was $2.19 \%$. In contrast, seropositivity of HBV in Indian study was observed to be $1.55 \%$ in 1996, which come down to $0.99 \%$ in $2002 .{ }^{10}$ Seroprevalence of HBsAg in various other Indian studies has been shown to range between 1.86 and 4\%. ${ }^{11-14}$ Seroprevalence of HBsAg in various studies in Pakistan has been shown to range between 1.55 and $8.4 \% .{ }^{15-19}$ In the present study the prevalence of seropositivity for anti-HCV was $0.2 \%$ in $2007,0.13 \%$ in 2008, $0.14 \%$ in 2009 and $0.43 \%$ in 2010 and overall prevalence was $0.25 \%$. Chronic HCV infection is recognized as a major public health problem. HCV transmitted primarily through blood exposure. In contrast to HBV, about 20 to $40 \%$ of HCV cases are acute and majority of them progress to chronic infection. The long-term risk of developing cirrhosis and hepatocellular carcinoma is greater in HCV-infected individual than those infected with HBV. The global prevalence of chronic HCV-infection is estimated to be approaching 3\%. Extremely low anti-HCV prevalence 0\% has been reported among the blood donors is UK and Scandinavia. The highest prevalence(28\%) has been reported in Egypt. ${ }^{20}$ Indian studies indicate that seroprevalence of HCV ranges between 0.4 and $1.09 \% .^{10-12,21}$ Several studies in Pakistan showed that the seroprevalence of HCV ranges between 0.07 and $4.9 \%{ }^{16,18,22,23}$

The incidence of HIV seropositivity was $0.0 \%$ in 2007, $0.06 \%$ in 2008, $0.07 \%$ in 2009 and $0.08 \%$ in 2010. The HIV seroprevalence in Indian scenario has been reported between 0.2 and 1\%. ${ }^{10,24}$ Two studies in Pakistan showed the prevalence of HIV $0 .{ }^{16,18}$

In an international study done in Yaounde, Cameroon 7.9\% of first-time blood donors were found positive for HIV, 10.7\% for HBV and 4.8\% for HCV. ${ }^{25}$ Another international study done at the Muhimbili National Hospital in Dar Es Salaam, Tanzania, showed prevalence of HIV, HBV and HCV in blood donors to be 3.8, 8.8 and 1.5\%, respectively. ${ }^{26}$

In the present study, the VDRL reactivity was $0.23 \%$ in 2007, 0.1\% in 2008, 0.12\% in 2009 and $0.17 \%$ in year 2010 . In the present study, incidence of HBsAg seropositivity was found to be the highest as compared with other transfusiontransmitted infection. During the 'window period' of hepatitis $\mathrm{B}$, detection of the IgM antibodies to the hepatitis B core antigen (Anti HBc-IgM) serves as a useful marker which indicates a recent infection. Therefore, it is strongly suggested that this marker must be utilized for screening of blood units to detect the hepatitis B during the window period. The reactivity of VDRL in the present study varied from 0.09 to $0.23 \%$. It is essential to exclude high-risk donors. The increased risk of TTI of HBV, HCV and HIV could be minimized by introduction of few more tests for screening of donor's sample. Introduction of NAT for HCV, HIV, anti-hepatitis B core antigen (Anti-HBc IgM) for HVB

Table 1: Seropositive donors of blood samples for HBsAg, HCV, HIV and VDRL

\begin{tabular}{lccrrr} 
& Year 2007 & Year 2008 & Year 2009 & Year 2010 & Total \\
\hline Total units & 3400 & 5326 & 5679 & \multicolumn{1}{c}{7561} & 21966 \\
HBsAg positive & $51(1.5 \%)$ & $69(1.37 \%)$ & $138(2.43 \%)$ & $224(2.96 \%)$ & $482(2.19 \%)$ \\
Anti-HCV positive & $7(0.2 \%)$ & $7(0.13 \%)$ & $8(0.14 \%)$ & $33(0.43 \%)$ & $55(0.25 \%)$ \\
HIV positive & $0(0.0 \%)$ & $3(0.06 \%)$ & $4(0.07 \%)$ & $6(0.08 \%)$ & $13(0.06 \%)$ \\
VDRL positive & $8(0.23 \%)$ & $5(0.1 \%)$ & $7(0.12 \%)$ & $13(0.17 \%)$ & $33(0.15 \%)$ \\
\hline
\end{tabular}

HBsAg: Hepatitis B surface antigen; HCV: Hepatitis C virus; HIV: Human immunodeficiency virus; VDRL: Venereal disease research laboratory 
infection is recommended to detect the infections during the window period and hence decrease the incidence of TTI.

HIV infection is a major public health problem world wide but it is still not common in Bangladesh, so attention should be paid toward the prevention of Hepatitis B and C virus as well as HIV. Therefore, with the implementation of strict donor selection criteria and use of sensitive laboratory screening tests, it may be possible to reduce the incidence of TTI in Bangladesh.

\section{REFERENCES}

1. Glynn SA, Kleinman SH, Wright DJ, Busch MP. International application of the incidence rate and window-period model (editorial). National heart, lung and blood institute retrovirus epidemiology donor study. Transfusion 2002;42:966-73.

2. Dodd RY, Notari EP, Stamer SL. Current prevalence and incidence of infectious disease markers and estimated windowperiod risk in the American Red Cross Blood Donor population. Transfusion 2002;42:975-79.

3. Klein HG. Will blood transfusion ever be safe enough? JAMA 2000;284:238-40.

4. Busch MP, Kleinman SH, Stramer SL. Nucleic acid amplification testing of blood donations. In: Sibinger S, Klein HG (Eds). Molecular biology in blood transfusion (1st ed). Netherlands: Kluwer Academic Publications 2000;81-103.

5. Fiebig EW, Busch MP. Emerging infections in transfusion medicine. Clin Lab Med 2004;24:797-823.

6. Alvarez M, Oyonarte S, Rodriguez PM, Hernandez JM. Estimated risk of transfusion-transmitted viral infections in Spain. Transfusion 2002;42:994-98.

7. Busch MP, Glynn SA, Stramer SL, et al. NHLBIREDS NAT study group: A new strategy for estimating risks of transfusiontransmitted viral infections based on rates of detection of recently infected donors. Transfusion 2005;45:254-64.

8. Pomper GJ, Wu Y, Synder EL. Risks of transfusion-transmitted infections. Curr Opin Hematol 2003;10:412-18.

9. Glynn SA, Kleinman SH, Wright DJ, Busch MP. For the NHLBI retrovirus epidemiology donor study: International application of the incidence rate/window-period model. Transfusion 2002;42:966-72.

10. Sharma RR, Cheema R, Vajpayee M, Rao U, Kumar S, Marwaha $\mathrm{N}$, et al. Prevalence of markers of transfusion transmissible diseases in voluntary and replacement blood donors. The National Medical Journal of India 2004;171:19-21.

11. Chandrasekaran S, Palaniappan N, Krishnan V, Mohan G, Chandrasekaran N. Relative prevalence of hepatitis B viral markers and hepatitis C virus antibodies (anti-HCV) in Madurai, South India. Indian Journal of Medical Sciences 2000;547:270-73.

12. Srikrishna A, Sitalakshmi S, Damodar P. How safe are our safe donors? Indian Journal of Pathology and Microbiology 1999;424:411-16.

13. Garg S, Mathur DR, Garg DK. Comparison of seropositivity of HIV, HBV, HCV and syphilis in replacement and voluntary blood donors in Western India. Indian Journal of Pathology and Microbiology 2001;444:409-12.

14. Choudhury N, Ramesh V, Saraswat S, Naik S. Effectiveness of mandatory transmissible diseases screening in Indian blood donors. Indian Journal of Medical Research 1995;101:229-32.

15. Ahmed F, Shah SHm Tariq M, Khan JA. Prevalence of hepatitis B carrier and HIV in healthy blood donors at Ayub Teaching Hospital, Pakistan. J Med Res 2000;39:91-92.

16. Khan MA, Rehman A, Ashraf M, Ali A, Ditta A. Prevalence of HBV, HCV and HIV in blood donors at Liaquatpur. Professional Med J 2006;13:23-26.

17. Khan Z, Raziq F, Aslam N. Prevalence of HIV in blood donors in NWFP. J Postgrad Med Inst 2002;16:187-89.

18. Mahmood MA, Khawar S, Anjum AH, et al. Prevalence of Hepatitis B, C and HIV infection in blood donors of Multan region. Ann King Edward Med Coll 2004;10:459-61.

19. Amin J, Yousuf H, Mumtaz A, et al. Prevalence of hepatitis B surface antigen and anti-hepatitis $\mathrm{C}$ virus. Professional Med J 2004:11(3):334-37.

20. Armstrong G, Alter M, McQuillang, et al. The past incidence of hepatitis $\mathrm{C}$ virus infection; implication for the future burden of chronic liver disease in United States. Hematol 2000;31:777-82.

21. Gupta N, Kumar V, Kaur A. Seroprevalence of HIV, HBV, HCV and syphilis in voluntary blood donors. Indian Journal of Medical Sciences 2004;58:255-57.

22. Ahmad S, Gull J, Akhtar K, Aftab BM, Khokhar MS. Prevalence of hepatitis $\mathrm{C}$ antibodies in healthy blood donors at services Hospital Lainore, Pakistan. Postgrad Med J 2002;13:18-20.

23. Aziz MS. Prevalence of anti-hepatitis $C$ antibodies and hepatitis B surface antigen in healthy blood bonors in Bastan Pak Armed Forces. Med J 2006;56(2):189-91.

24. Paramjit K, Basu S. Transfusion-transmitted infections: Existing and emerging pathogens. Journal of Post Graduate Medicine 2005;51:146-51.

25. Mbanya DN, Takam D, Ndumoe PM. Serological findings amongst first-time blood bonors in Yaounoe, Cameroon is safe bonotion a reality or a myth. Transfusion Medicine 2003;13: 267-73.

26. Matee Mecky, Magesa Pius M, Lyamuya Eligius F. Seroprevalence of human immunodeficiency virus, hepatitis B and $\mathrm{C}$ viruses and syphilis infections among blood donors at the Muhimbili National Hospital in Dar Es Salaam. Tanzania BMC Public Heath 2006;6:21. 